\title{
Avaliação quali-quantitativa de espécies arbóreas e arbustivas em duas praças do bairro Noé Trajano,
} Patos-PB

\author{
Geovanio Alves da Silva ${ }^{1 *}$, Joedla Rodrigues de Lima ${ }^{1}$, Iara Cristina Araújo Rocha ${ }^{1}$, Vinícius Staynne \\ Gomes Ferreira ${ }^{1}$, Elizabeth de Oliveira ${ }^{1}$
}

\begin{abstract}
RESUMO: O processo de avaliação quali-quantitativa da arborização, depende da realização de inventários que forneçam informações sobre os seus componentes. Diante disto, este estudo se propõe a diagnosticar o estado fitossanitário e dendrológico das árvores, assim como indicar os possíveis conflitos existentes entre a arborização local e as estruturas urbanas, em duas praças do bairro Noé Trajano na cidade de Patos-PB, avaliando os seguintes parâmetros, diversidade florística, frequência de espécies, porte dos indivíduos e estado fitossanitário. Com relação ao aspecto do troco, foi observado apenas (um) indivíduo tortuoso em cada praça e referente a exposição de raízes, apenas uma única árvore, apresentou este conflito. Com relação as injúrias foram observadas de danos nos caules das árvores causados pelo excesso de tempo do tutor acarretando seu estrangulamento e também se identificou a presença de pregos. Quanto ao porte, a maior parte dos indivíduos foram classificados de porte pequeno $(55,55 \%)$, com predomínio de Azadirachta indica (Nim indiano). As duas praças totalizam-se 99 árvores, demonstram adequado manejo na maioria dos indivíduos.
\end{abstract}

Palavras-chave: arborização, inventário, espécies exóticas.

\section{Qualitative and quantitative evaluation of tree and shrub species in two squares of the neighborhood Noé Trajano, Patos-PB}

\begin{abstract}
The process of qualitative and quantitative assessment of afforestation depends on the carrying out of inventories that provide information about its components. Therefore, this study proposes to diagnose the phytosanitary and dendrological state of the trees, as well as to indicate the possible conflicts between the local forestation and the urban structures, in two squares of the neighborhood Noé Trajano in the city of Patos-PB, evaluating the following parameters, floristic diversity, frequency of species, size of individuals and phytosanitary status. Regarding the aspect of the change, only one tortuous individual was observed in each square and referring to the exposure of roots, only a single tree, presented this conflict. Regarding the injuries were observed of damage in the stalks of the trees caused by the tutor's excessive time causing his strangulation and also the presence of nails was identified. Regarding the size, most of the individuals were classified as small (55.55\%), with predominance of Azadirachta indica (Indian Nim). The two squares with a total of 99 trees, demonstrating adequate management in most individuals.

Keywords: afforestation, inventory, exotic species.
\end{abstract}

\section{INTRODUÇÃO}

As áreas verdes são componentes relevantes para o da população urbana, nestas áreas as árvores são de suma importância tanto por questões ambientais, estéticas como para o bem-estar humano Silva et al. (2017). Conforme Tischer et al. (2014) as praças e jardins ajudam na retenção e ciclagem da água, agem como quebra ventos, além de oferecer condições de sobrevivência para fauna da região.

Para Silva et al. (2017) também se inclui como benefícios da arborização a criação de áreas agradáveis climaticamente em contraste com as áreas construídas, incluindo a atenuação sonora e retenção de partículas de poeira.

Contudo para que isto ocorra é necessário a realização da implantação e manejo correto da arborização. Sendo assim,, não basta implantar árvores reconhecendo sua importância, deve-se agir com prudência, pois as mesmas podem entrar em conflito com redes elétricas, encanamentos, rede de esgoto, entre outros (SOUZA et al., 2016). Além destes, são encontrados na arborização urbana conflitos como podas drásticas, indivíduos atacados por insetos ou fungos além de árvores que apresentam injúrias físicas (RIBEIRO, 2009). O que pode acarretar acidentes provindos de queda de galhos ou árvores, com o risco de morte de animais ou pessoas.

O planejamento, a implantação e a manutenção da arborização urbana devem seguir normas, especificações e técnicas que satisfaçam as necessidades da população Cechetto et al. (2015), abrangendo a segurança. Há necessidade, pela admiração urbana, da criação de leis específicas para a implantação adequada de indivíduos arbóreos,

Recebido em 31/07/2018; Aceito para publicação em 01/11/2019

${ }^{1}$ Universidade Federal do Ceará

2 Instituto Federal do Ceará

*E-mail: lumanunes20@hotmail.com 
assim como a realização do manejo correto das árvores (LACERDA et al. 2013).

O processo de avaliação quali-quantitativa da arborização, depende da realização de inventários que forneçam informações sobre os seus componentes (REDING et al., 2010). O inventário tem como meta descrever as circunstâncias que se encontram os indivíduos arbóreos e arbustivos de determinado ambiente, assim como é essencial para orientar o planejamento adequado da arborização (ARAÚJO et al., 2009). Informando quando preciso a realização de podas, de tratamentos fitossanitários e retirada de indivíduos mortos (MELO et al., 2007). Diante disso, este estudo se propôs a diagnosticar o estado fitossanitário e dendrométrico das árvores, assim como indicar os possíveis conflitos existentes entre a arborização local e as estruturas urbanas, em duas praças do bairro Noé Trajano na cidade de Patos-PB, avaliando fatores como número, diversidade e frequência de espécies, porte dos indivíduos e estado fitossanitário.

\section{MATERIAL E MÉTODOS}

A pesquisa foi realizada na cidade de Patos/PB, situada mesorregião Sertão Paraibano (Figura 1). De acordo com o Instituto Brasileiro de Geografia e Estatística IBGE (2010), a cidade possui cerca de $473,056 \mathrm{~km}^{2}$ e abriga uma população de aproximadamente 100.674 habitantes. Segundo a classificação de Köppen Alvares et al., 2014, o clima da região é do tipo BSh, quente e seco. A vegetação no entorno do município é caatinga com presença de espécies xerófilas, decíduas e presença de espinhos (PEREIRA FILHO et al., 2010).

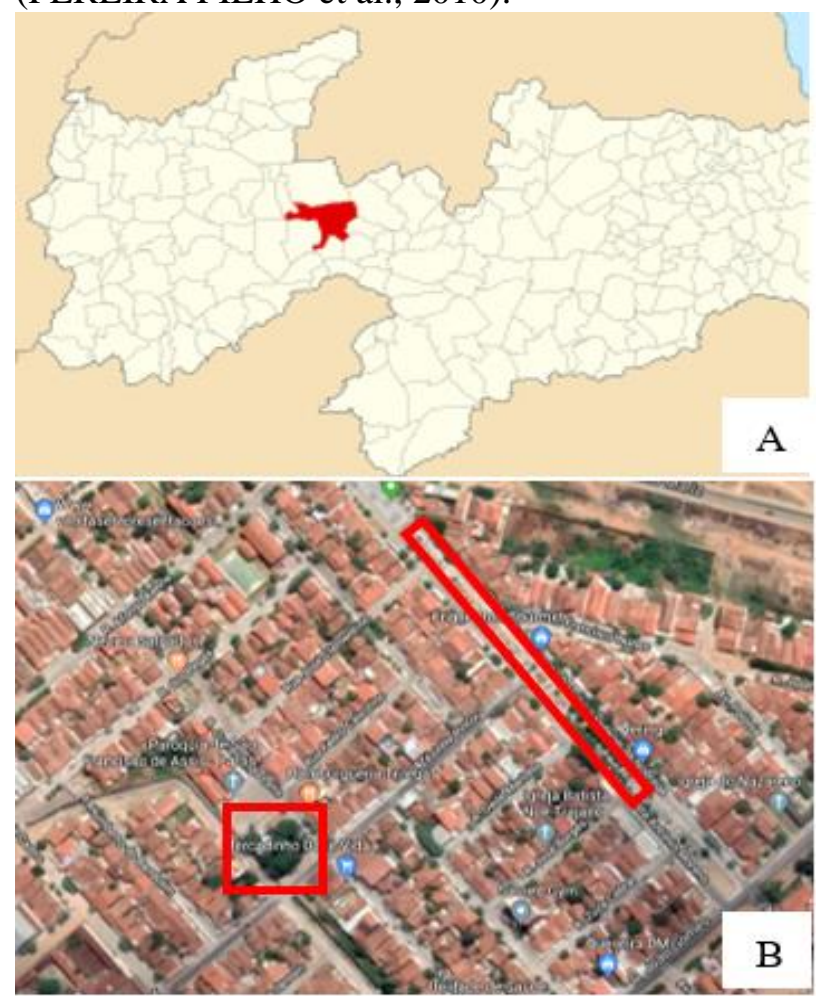

Figura 1: A) Município de Patos. B) Áreas amostras
Os dados da pesquisa foram coletados no mês de Março/2018, onde se identificou e avaliou apenas os indivíduos arbóreos e arbustivos das praças Noé Trajano (700'35,3' 'S $37^{\circ} 17^{\prime} 18,2^{\prime}$ ' $\left.\mathrm{W}\right)$ e Gilberto da Silva Oliveira (700'32.7'S 37¹7'11.9' W), ambas no bairro do Noé Trajano em Patos-PB (Figura 2).
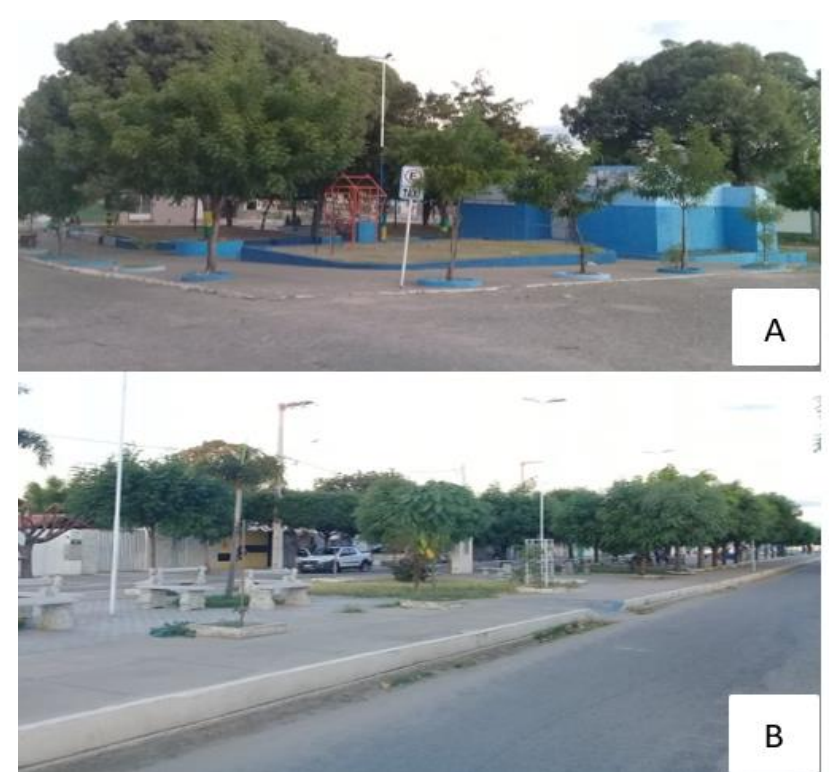

Figura 2: A) Praça Noé Trajano, B) Praça Gilberto da Silva Oliveira.

Para o registro e coleta de dados de trabalho de campo foram utilizadas planilhas, trena, fita métrica, câmera digital e baliza de 6 metros. No caso de indivíduos acima desta altura, a mesma foi obtida por meio de estimativa. A identificação da maioria das espécies aconteceu no momento da coleta dos dados, as que não foram identificadas, colheu-se material botânico para posterior identificação no herbário do CSTR/UFCG.

Para a avaliação quantitativa dos indivíduos arbóreos, inicialmente realizou-se a contagem e identificação dos indivíduos presentes na área. Em seguida, foi medida a circunferência na altura do peito (CAP) com trena e em seguida os dados foram convertidos para diâmetro a altura do peito (DAP). A altura da primeira bifurcação foi medida com fita métrica e a altura total das árvores $(\mathrm{H})$ com a baliza (NÓBREGA et al, 2014).

Para a avaliação qualitativa as espécies foram classificadas quanto ao aspecto físico-sanitário observando a qualidade do tronco, copa, se há injúrias e exposições de raízes. $\mathrm{E}$ o porte avaliando altura classificado em pequeno (até 4 metros), médio (de 4 a 7 metros) e grande (maior que 7 metros), conforme (ALENCAR, 2012).

\section{RESULTADOS E DISCUSSÕES}

Foram amostrados 99 indivíduos de porte arbóreo e arbustivo nas praças do bairro Noé Trajano na cidade de Patos PB. 
Conforme pode ser observado na Tabela 1, referente a praça Noé Trajano, foram identificados 27 indivíduos distribuídos em sete espécies, das quais três são nativa da Caatinga sendo elas Poincianella pyramidalis (Catingueira), Tabebuia aurea (Craibeira) e Bauhinia forficata (Pata de vaca) na qual a Craibeira é a mais abundante com $(22,22 \%)$ de presença na praça. Em relação às exóticas o Azadirachta indica (Nim indiano) obteve destaque com $(48,15 \%)$ de representatividade.

Considera-se que a frequência de uma única espécie não deve ultrapassar a 15\% (TISCHER; FORTE; PEDROSO-DE-MORAES 2014). Por razões estéticas e fitossanitárias, deve-se estabelecer o número e a proporção para cada espécie em relação ao total de árvores plantadas (MILANO; DALCIN, 2000; REDING et al., 2010), pois o ataque de pragas e doenças pode acarretar na morte de vários indivíduos.

Dentre as espécies nativas encontradas a Bauhinia forficata Link (Pata de vaca) a é considerada ameaçada de extinção, sendo ela, (SILVA; LEITE; TONELLO, 2014). De acordo com Sousa et al. (2014), é recomendável utilizar espécies nativas, preferencialmente nativas regionais, para o possível estabelecimento de corredores ecológicos.
Além da interação com a fauna e flora local, as espécies nativas implantadas no ambiente urbano podem ser utilizadas em atividades de educação ambiental, evidenciando, por exemplo, a necessidade de conservação de espécies ameaçadas de extinção e as funções que as árvores podem exercer no ecossistema natural.

Outra importância da inserção de espécies nativas nas praças, bosque e avenidas é devido às mesmas estabelecem o controle biológico e equilíbrio dos ecossistemas. Diante o levantamento das espécies nas praças, é possível observar que dentre as espécies nativas a Tabebuia aurea (Craibeira), é a única que oferece sombra, as demais possuem baixa estatura.

Com relação ao manejo é verificado a necessidade da retirada dos tutores nas árvores que já estão bem estabelecidas e com diâmetro e altura satisfatórios, não havendo o risco de haver tombamento o que não justifica o uso do tudo. Quanto às exóticas identificadas, o caso dos indivíduos de Azadirachta indica (Nim indiano), devido seu rápido crescimento, é preciso realizar poda de elevação para facilitar o passeio dos pedestres na praça.

Tabela1: Dados dendrométricos de indivíduos arbóreos existentes na praça velha do Noé Trajano. (700’35,3'’ $\mathrm{S} 37^{\circ} 17^{\prime} 18,2^{\prime}$ 'W). Patos/PB.

\begin{tabular}{|c|c|c|c|c|}
\hline \multirow[b]{2}{*}{ Espécie } & \multirow[b]{2}{*}{ Nome científico } & \multirow[b]{2}{*}{ Origem } & \multicolumn{2}{|c|}{ Praça 1} \\
\hline & & & F.A. & F.R $\%$ \\
\hline Acácia & Senna siamea $\mathrm{L}$. & Exôtica & 3 & 11,11 \\
\hline Catingueira & $\begin{array}{l}\text { Poincianella pyramidalis (Tul.) L.P. } \\
\text { Tabebuia aurea (Silva Manso) Benth. \& Hook. f. ex S. }\end{array}$ & $\begin{array}{l}\text { Nativa } \\
\text { Nativa }\end{array}$ & 1 & 3,70 \\
\hline Craibeira & Moore & & 6 & 22,22 \\
\hline Flamboyant & Delonix regia (Bojer ex Hook) Raf. & Subespontânia & 2 & 7,41 \\
\hline Nim & Azadirachta indica A. Juss & Exôtica & 13 & 48,15 \\
\hline Pata de vaca & Bauhinia forficata Link. & Nativa & 1 & 3,70 \\
\hline Tamarino & Tamarindus indica $L$. & Exotica & 1 & 3,70 \\
\hline Total & & & 27 & 100 \\
\hline
\end{tabular}

F.A = frequência absoluta; F.R. = frequência relativa $(\%)$

Já a espécie Delonix regia (Flamboyant) é de origem subespontânea com domínios fitogeográficos em outros biomas do Brasil, e por isso são consideradas naturalizadas, segundo Iganci (2012) e Lewis (2011), esta espécie possui floração vistosa e atrativa, muito utilizada para ornamentação de parques e ruas, além de fornecer sombreamento (SILVA, 2009).

Com relação à praça Gilberto da Silva Oliveira foram observados e identificados 72 indivíduos. Dentre todos o Azadirachta indica (Nim indiano) apresentou maior número de indivíduos, equivalente a $(52,78 \%)$. As árvores de origem nativa o Tabebuia impetiginos (Ipê) apresentou destaque diante as outras com $(11,11 \%)$ de representatividade.

As diversidades de espécies desempenham diferentes funções que ajudam na melhoria da qualidade ambiental da cidade (ALENCAR, 2012), donde reside a importância de haver diversidade nas praças, seja pela retenção de partículas, sombreamento, minimização da temperatura e proporcionar um ambiente visualmente mais atrativo (NÓBREGA et al, 2014).

Contudo o alto percentual de uma mesma espécie como é o caso do Nim indiano nesta praça, pode acarretar problemas, como mencionado anteriormente. Lima Neto e Souza (2009) alertam 
que a alta concentração de uma mesma espécie é um perigo na composição da arborização de praças,

parques e ruas, na qual aumenta o risco de doenças e pragas dos indivíduos que compõe a arborização.

Tabela 2: Dados dendrométricos de indivíduos arbóreos existentes na praça Gilberto da Silva Oliveira. (700’32.7’'S 37¹7’11.9”'W). Patos/PB.

\begin{tabular}{|c|c|c|c|c|}
\hline Nome Vulgar & Nome Científico & Origem & F.A. & F.R. \\
\hline Catingueira & Poincianella pyramidalis (Tul.) L.P. & Nativa & 1 & 1,39 \\
\hline Chuva de ouro & Cássia fístula $L$. & Exótica & 2 & 2,78 \\
\hline Ciriguela & $\begin{array}{c}\text { Spondia purpurea L. } \\
\text { Tabebuia aurea (Silva Manso) Benth \& Hook. f. ex S. }\end{array}$ & Nativa & 1 & 1,39 \\
\hline Craibeira & Moore & Nativa & 2 & 2,78 \\
\hline Floboyan & Delonix regia (Bojer ex Hook) Raf. & Subespontânea & 4 & 5,56 \\
\hline Ipê & Tabebuia impetiginos a (Mart. Standl.) & Nativa & 8 & 11,11 \\
\hline Manga & Mangifera indica $\mathrm{L}$. & Exotica & 3 & 4,17 \\
\hline Moringa & Moringa oleífera Lam. & Exótica & 1 & 1,39 \\
\hline Mulungu & Erythrina velutina Wild. & Nativa & 1 & 1,39 \\
\hline Nim & Azadirachta indica A. Juss & Exótica & 38 & 52,78 \\
\hline Sagu de jardim & Cycas revoluta thunberg & Exótica & 4 & 5,56 \\
\hline Tamareira de jardim & Phoenix roebelinii & Exótica & 6 & 8,33 \\
\hline Cola & Cordia abyssinica $\mathrm{R}$. Br. & Exótica & 1 & 1,39 \\
\hline Total & & & 72 & 100 \\
\hline
\end{tabular}

Observou-se, para o diâmetro a altura do peito na praça Noé Trajano (Figura 3 A), a predominância de indivíduos com DAP de até $11 \mathrm{~cm}$ prevaleceu, equivalendo a (48\%). Isto indica que a maior parte dos componentes arbóreos da praça se encontra na fase jovem.
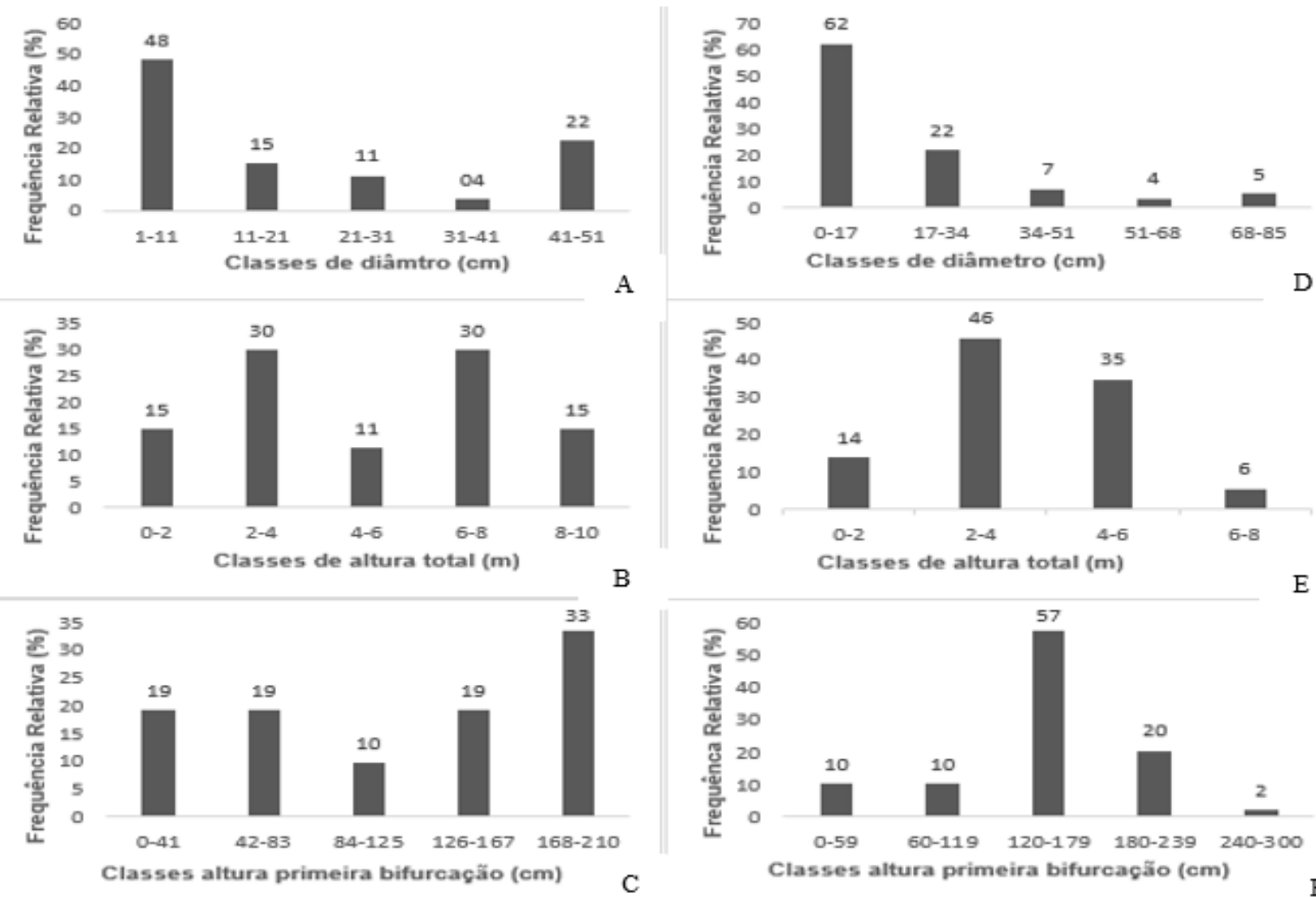

Figura 3: Frequências observadas para as variáveis, diâmetro a altura do peito, altura total, altura da primeira bifurcação. Praça Noé Trajano (a,b,c); e praça Gilberto da Silva Oliveira (d,e,f). 
Analisadas as medidas obtidas para a altura total (Figura 3 B), os intervalos de classes que apresentaram maiores valores, foram nas classes de $(2-4 \mathrm{~m})$ e $(6-8 \mathrm{~m})$ equivalendo a $(30 \%)$ de indivíduos nestas respectivas classes em ambos os intervalos equando verificada a altura da primeira bifurcação (Figura $3 \mathrm{C}$ ), percebeu-se que em (33\%) dos indivíduos amostrados ocorre "entre $168-210 \mathrm{~cm}$ ". Não foi verificado conflito entre a fiação com as copas das árvores. Com relação aos dados dendrométricos da praça Gilberto da Silva Oliveira (Figura 3 D, 3 E, 3F), observa-se referente ao diâmetro dos indivíduos que a classe que obteve destaque foi a primeira com indivíduos de até $17 \mathrm{~cm}$ equivalendo a $(62 \%)$ da amostragem. Para a altura total prevaleceu a faixa de $2-4 \mathrm{~m}(46 \%)$ e referente à altura da primeira bifurcação houve maior número de indivíduos bifurcados a altura de 120-179 cm (57\%). O ideal da altura da primeira bifurcação é acima de $180 \mathrm{~cm}$ desse modo facilita a passagem dos pedestres, quando menor que isso, deve ser realizada poda de formação (SÃO PAULO, 2005).Agrupando todos os indivíduos das duas praças totaliza-se 99 árvores. Para o aspecto do tronco, foi observado apenas 1 indivíduo tortuoso em cada praça. De acordo com Salvi et al. (2011), com relação ao tronco, o ideal é que seu desenvolvimento ocorra de forma livre, ou que possua poucas podas de correção, tendo em vista que estas técnicas são mais utilizadas em arborização de canteiros em vias públicas. Contudo, em praças, a poda nem sempre se faz necessária, devendo-se permitir que as espécies se desenvolvam de acordo com suas características naturais (SILVA et al., 2017).

Referente a exposição de raízes, apenas uma única árvore, apresentou este conflito. De acordo com Gonçalves et al. (2004) este é um órgão subterrâneo, com função de absorção de água e nutrientes, além de dar sustentação à planta, sendo necessário sua boa fixação no solo, para evitar tombamentos. Foram observadas ainda injúrias nos caules das árvores $(4,04 \%)$, presença de pregos e estrangulamento causado pelo excesso de tempo do tutor, isso pode acarretar na entrada de pragas e patógenes causando doenças nos indivíduos (Figura 4).
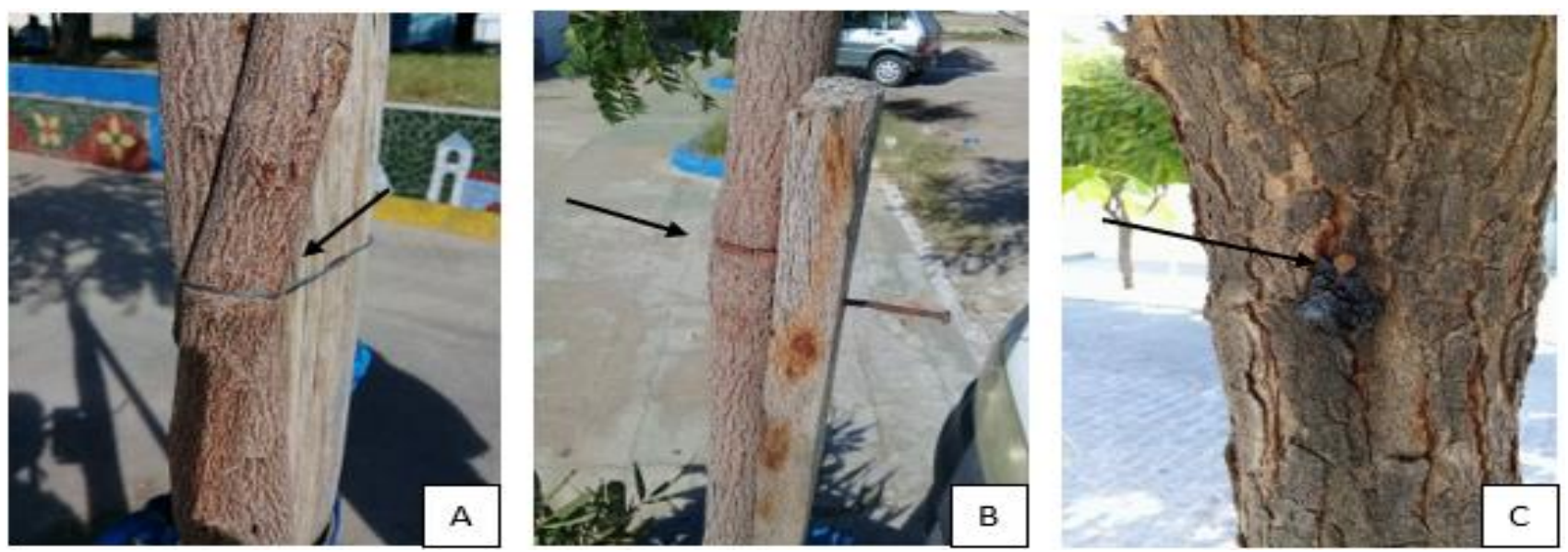

Figura 4: Idendificação de injúrias. A) Necessidade de retirada do tutor, B) Indivíduo estrangulado, C) Presença de prego na árvore.

Quanto ao porte, a maior parte dos indivíduos foram classificados de porte pequeno $(55,55 \%)$, com predomínio de Azadirachta indica, além do mais esta espécie é de rápido crescimento e faz parte da cultura local práticas de podas contínuas.

Ainda pode-se dizer que este resultado remete ao fato de que ambas as praças contêm indivíduos jovens. 35,35\% dos indivíduos foramclassificados de médio porte e $9,10 \%$ de grande porte (Figura 5). Resultados diferentes foram encontrados por (Nobrega, 2014) em estudos realizados no parque religioso Cruz da Menina em Patos-PB, realizado em 2014, no qual o maior número de indivíduos foi encontrados com porte médio $(47,0 \%)$ que, segundo o autor, se deve à grande quantidade de Prosopis juliflora. 


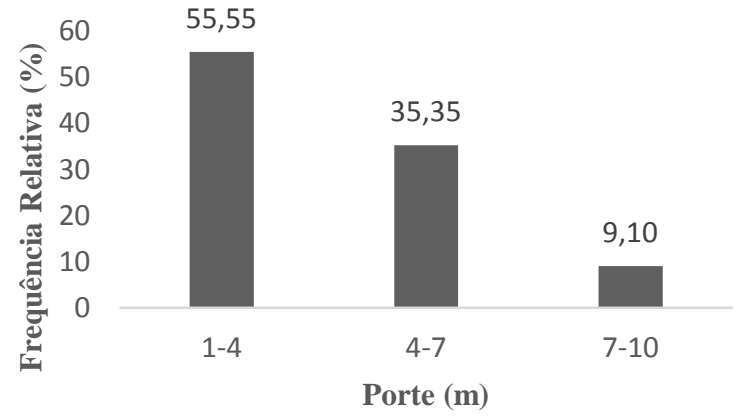

Figura 5: Frequência relativa do porte das árvores das duas praças do bairro Noé Trajano.

\section{CONCLUSÃO}

Nas duas praças totalizam-se 99 árvores distribuídas em 7 espécies.

$78,8 \%$ do total de indivíduos são exóticas, com predominância da Azadirachta indica. Recomendase o plantio de espécies nativas diferenciadas para evitar a uniformidade.

A maioria dos indivíduos se encontram na fase jovem e apresentam porte baixo.

Ambas as praças demonstram adequado manejo na maioria dos indivíduos.

\section{REFERÊNCIAS}

ALENCAR, L.S. Inventário quali-quantitativo da arborização urbana em São João do Rio do Peixe PB. Patos: Universidade Federal de Campina Grande, 2012. 41p. Trabalho de Conclusão de Curso.

ALVARES, C. A.; STAPE, J. L.; SENTELHAS, P. C.; GONÇALVES, J. L. M.; GERD SPAROVEK, G. Köppen's climate clasification map for Brazil. Meteorologische Zeit, v. 22, n. 6. Stuttgart, Alemanha. 2014. p 711-728.

ARAÚJO, A. C.; RIBEIRO, I. A. M.; MORAIS, M. S.; MORAIS, M. S. ARAÚJO, J. L. O. Análise qualiquantitativa da arborização no bairro Presidente Médici, Campina Grande-PB. . Revista da Sociedade Brasileira de Arborização Urbana. Piracicaba - SP, v.4, n.1, p. 133-144, 2009

CECCHETTO, C.T.; CHRISTMANN, S.S.; OLIVEIRA, T.D. Arborização Urbana: Importância e Benefícios no Planejamento Ambiental das Cidades.,In: XVI Seminário Internacional de Educação no Mercosul. Cruz Alta, 2015.

GONÇALVES , E. O.; PAIVA, H. N.; GONÇALVEZ, W.; JACOVINE, L. A G. Avaliação qualitativa de mudas destinadas à arborização urbana no estado de Minas Gerais. R. Árvore, Viçosa-MG, v.28, n.4, p.479- 486, 2004.
IBGE. Censo Demográfico 2010. Disponível em: <http://www.ibge.gov.br/home/estatistica/populacao/cens o2010/resultados_dou/PB2 010.pdf>. Acesso em: 28/08/ 2018.

IGANCI, J.R.V. Pithecellobiumin. Lista de Espécies da Flora do Brasil. Jardim Botânico do Rio de Janeiro. Disponível em:

<http://floradobrasil.jbrj.gov.br/2012/FB083609>. Acesso em 19 mar. 2018

LACERDA, M. A de; SOARES, F. de S.; COSTA, J. P. M.; MEDEIROS, R. de S.; MEDEIROS, E. N. de.; CARVALHO, J. A. de.; SILVA, Z. L. da. Levantamento florístico da arborização urbana nas principais vias públicas do Município de Boa Ventura - PB. Revista Brasileira de Gestão Ambiental - RBGA, Pombal - Pb Brasil, v. 7, n. 4, p. 12 - 16, out./dez. 2013.

LEWIS, G.P. Lista de Espécies da Flora do Brasil. Jardim Botânico do Rio de Janeiro. Disponível em: <http://floradobrasil.jbrj.gov.br/2011/FB109818>. Acesso em 19 mar. 2018.

LIMA NETO, E.M.; SOUZA, R.M. Índices de densidade e sombreamento arbóreo em áreas verdes públicas de Aracaju, Sergipe. Revista Da Sociedade Brasileira De Arborização Urbana, Piracicaba, v.4, n.4, p.47-62, 2009.

MELO, R.R.; LIRA FILHO J.A.; RODOLFO JÚNIOR, F. Diagnóstico Qualitativo e Quantitativo da Arborização Urbana no Bairro Bivar Olinto, Patos, Paraíba. Revista da Sociedade Brasileira de Arborização Urbana, Piracicaba, v.2, n.1, p.64-80. 2007.

NÓBREGA, C. C., et al. Análise quanti-qualitativa das espécies arbóreas presentes no parque religioso cruz da menina, Patos/PB. Enciclopédia Biosfera. Centro Científico Conhecer - Goiânia, v.10, n.18; p. 2014.

PEREIRA FILHO, J. M.; BAKKE, O. A. Produção de forragem de espécies herbáceas da caatinga. In. Uso Sustentável e Conservação dos Recursos Florestais da Caatinga. GARIGLIO, et al (org.) 2.ed. 630.3. Brasília: Serviço florestal brasileiro, 2010, 368 p. Disponível em: <http://www.mma.gov.br/estruturas/sfb/_arquivos/web_u 
so_sustentvel_e_conservao_dos_recursos_florestais_da_c aatinga_95.pdf $>$ Acesso em: 28/07/2017

REDING, C. G.; VOGEL, C.; TROJAHN, C. D. P.; GRACIOLI, S. J. L. Análise da arborização urbana em cinco praças do município de Cachoeira do Sul, RS. Revista Brasileira de Arborização Urbana, v.5, n.3, p.149-164, 2010.

REDING, C. G.; VOGEL, C.; TROJAHN, C. D. P.; GRACIOLI, S. J. L. Análise da arborização urbana em cinco praças do município de Cachoeira do Sul, RS. Revista Brasileira de Arborização Urbana, v.5, n.3, p.149-164, 2010.

RIBEIRO, F.A.B.S. Arborização urbana em Uberlândia: percepção da população. Revista da Católica, Uberlândia-MG, v.1, p.224-237, 2009.

SALVI, L.T.; HARDT, L.P.A.; ROVEDDER, C.E.; FONTANA, C.S. Arborização ao longo de ruas - Túneis Verdes - em Porto Alegre, RS, Brasil: avaliação quantitativa e qualitativa. Revista Árvore, v.35, n.2, p.233-243, 2011.

SÃO PAULO. Secretaria Municipal do Verde e do Meio Ambiente. Manual técnico de arborização urbana. 2.ed. São Paulo: Nacional, 2005. 45p

SILVA, GILVAN C. da. Distribuição espacial do flamboyant, espécie exótica da Mata Atlântica, no Campus I da Universidade Federal da Paraíba. Universidade Federal da Paraíba - Centro de Ciências Exatas e da Natureza Curso de Graduação em Geografia, 2009.
SILVA, J. S.; VIANNA, K. R.; BÜNDCHEN, M. Diagnóstico qualitativo e quantitativo da vegetação arbórea da Praça dos Açorianos, Porto Alegre, RS. ScientiaTec: Revista de Educação, Ciência e Tecnologia do IFRS, v.4, n.2, Edição Especial, p: 208221, set 2017.

SILVA, L. D. C. et al. Inventário e diagnóstico da arborização em quatro áreas públicas na cidade de Guaçuí - ES. Revista da Sociedade Brasileira de Arborização Urbana, Piracicaba - SP, v.12, n.2, p. 117-128, 2017.

SILVA, T. G.; LEITE, E. A.; TONELlO, K. C. Inventário da arborização urbana no município de Araçoiaba da serra, SP. Revista da Sociedade Brasileira de Arborização Urbana, Piracicaba - SP, v.9, n.4, p 151-169, 2014.

SOUSA, R. de C.; AGUIAR, O. T. de; SILVA, L. T. A. da; SILVA, L. A.; MARRA, R. C. Avaliação qualiquantitativa da arborização na praça Agostinho Nohama, bairro Lauzane Paulista, São Paulo - SP. Revista da Sociedade Brasileira de Arborização Urbana, Piracicaba, v. 9, n. 1, p. 92-107, 2014.

SOUZA, M. A. S. et al. Percepção da população relacionada à arborização urbana de praças no centro da cidade de Patos - PB. ACSA, Patos-PB, v.12, n.4, p.368375, outubro-dezembro, 2016

TISCHER, J. C., FORTE, A. R., PEDROSO-DEMORAES, C. Análise qualiquantitativa de indivíduos arbóreos das praças centrais do município de Leme, SP. Revista da Sociedade Brasileira de Arborização Urbana, Piracicaba - SP, v.9, n.3, p 49-64, 2014. 